\title{
Networked Media Collectivities. The Use of Media for the Communicative Construction of Collectivities Among Adolescents
}

\author{
Thomas N. Friemel and Matthias Bixler
}

\subsection{INTRODUCTION}

People use media to communicate and thereby create and maintain social relations in two ways. First, media provide technological means to bypass time and space and enable otherwise unconnected individuals to interact. Second, media provide topics for communication. Hence, media are able to fulfil two functions for relationships between individuals and for the collectivities they are part of at the same time: as a technology for and as

T.N. Friemel $(\bowtie) \cdot$ M. Bixler

Institute of Mass Communication and Media Research, University of Zurich, Andreasstrasse 15, 8050 Zurich, Switzerland

e-mail: th.friemel@ipmz.uzh.ch

M. Bixler

e-mail: m.bixler@ipmz.uzh.ch

(C) The Author(s) 2018

A. Hepp et al. (eds.), Communicative Figurations,

Transforming Communications - Studies in Cross-Media Research, https://doi.org/10.1007/978-3-319-65584-0_8 
subject of communication. For decades, these two aspects were separated by two distinct types of media. For example, the telephone can be seen as a traditional medium that provides the technology for mediated interpersonal communication and to bypass geographical distance. In contrast to this, the content of newspapers, TV and other mass media are typically referred to as important subjects for everyday conversation. Theoretical concepts and empirical research on the social context and social relevance of media use have a long history (Friemel 2013). Based on the general trend towards an increasing relevance of media for our society (Esser and Strömbäck 2014; Lundby 2014), collectivities are affected by mediatization as well (Couldry and Hepp 2017).

The current mediatization might not only be a gradual shift by means of a quantitative increase of media use and media references: we assume that the fundamental change in media environment will lead to a qualitative change of how collectivities are constructed by and through media. For example, the online social networking platforms that have emerged in the past decade have made apparent how numerous and interwoven our personal networks are. They enable us to display activities, preferences and relationships to friends as well as to more distant persons or even strangers in a way which was not possible with any media before. Online media also facilitate an easy sharing of mass media content through computer-mediated interpersonal communication and thereby blur the above-mentioned line between the two kinds of media (i.e. technology and content). Hence, the emergence and pervasiveness of 'new' digital communication technologies will change the way people connect and communicate by various means. Owing to the expected fundamental change of how social collectivities are constructed, this trend can be referred to as deep mediatization (cf. Chap. 2).

With respect to our subject of collectivities, we regard the following trends in the changing media environment as the most important: (1) Connectivity. Digital communication technologies such as social network services (SNS) and instant messengers (IM) empower people to connect with a vast number of others and relax the boundedness of time and space for social interaction. A consequence of this trend is that social borders are blurring and personal networks may become more diverse (Erickson 2003; Gruzd et al. 2011). (2) Omnipresence. The development of Internet-enabled mobile devices to make these technologies available 
on the go. For many people, this means they have become accessible almost anywhere and at any time (van Eimeren 2013). At the same time, people permanently create digital traces that may be tracked by various actors and create new possibilities for intended but also unintended control. Managing this omnipresence is likely to become a major challenge for individuals as well as collectivities. (3) Differentiation. Omnipresent connectivity is not limited to a single medium but is diversified across several communication technologies (DIVSI 2014). At the same time, the number of subjects to communicate on vastly increases owing to the large number of digital media outlets (e.g. special interest media) and the abundance of user-generated content. It is likely that beside algorithmic content selection the selection by collectivities will become of increasing importance (Friemel 2013). (4) Datafication. The possibility to embed (mass) media content in computer-mediated interpersonal communication and the large amount of user-generated data leads to new forms of communication that let previously distinct media types converge (Jensen 2010), but also set the ground for entirely new ways in which media are used. All four trends are likely to alter the way people communicate, establish relationships, collectivities and social capital.

In order to track these trends and study the consequences of deep mediatization of collectivities, we develop the theoretical concept of networked media collectivities and an empirical research design based on social network analysis. The goal of this contribution is to introduce the theoretical concept and the respective research design and to provide an initial measure to enable future comparisons. The next two sections discuss the literature related to this endeavour and define the most important terms. Section 8.2 focuses on the concept of networked media collectivities and how these are constructed. This sets the ground for the discussion of how the changing media environment has an impact on social capital emerging from the collectivities (Sect. 8.3). Based on this literature review and theoretical reasoning, five research questions are derived in Sect. 8.4. Section 8.5 explains the research design of our study and introduces the chosen sample and methods. The results are presented and discussed in two subsequent sections. In Sect. 8.6 relevant descriptives for media use and communication about media content are discussed, and Sect. 8.7 provides insight into the network perspective of media-related communication. Section 8.8 summarizes our findings. 


\subsection{Mediatized Construction of Collectivities}

Drawing on a definition proposed by Couldry and Hepp, we use the term collectivity to describe a 'figuration of individuals that share a certain meaningful belonging that provides a basis for action- and orientation-in-common' (Couldry and Hepp 2017: 168). They further distinguish between media-based collectivities and mediatized collectivities. The first are only made possible by the use of media technologies. The latter are able to exist without the use of media in principle, but are substantially shaped by media-related communication (Couldry and Hepp 2017: 170). Purely media-based and purely mediatized collectivities can be regarded as two theoretical poles of a continuum encompassing the phenomenon of collectivism as defined above. In reality, they are most likely to be encountered as hybrids or in transition from one type to the other.

The research presented in this chapter deals with collectivities in which both media and strong social relationships play a crucial role for their members. Therefore we put a special focus on the actor constellations that emerge from media-related communication on the one hand and friendship on the other. To be able to identify several actor constellations and how they are interrelated with media use as well as with each other, we apply a social network approach. According to Lin, we can define a collectivity as 'a social network with members as actors' (Lin 2008: 62), which includes the necessity that the actors are at least partially directly linked to each other. The loosest link hereby is the possibility to perceive others and their actions. More obvious links would be any form of direct interaction, such as conversations. The relevance of these direct links can be explained by the criteria Baym lists for online communities and networked collectivism. In addition to the shared practice by means of using a specific medium, this includes social norms (Baym 2015), since social norms require at least a minimal level of perception of others. Hence, direct links become a necessary prerequisite for what we call collectivities.

In a broad understanding, any audience could be seen as a mediabased collectivity since it has an orientation towards the respective media content in common (Grunig and Stamm 1973: 567). However, to emphasize the aspect of direct orientation to each other and respective actions, we subsequently use the term of networked media collectivities. Thus, these are defined as networked sets of actors with shared 
communicative practices (e.g. a strong orientation towards specific media contents and/or specific media technologies). Examples are a group of people who discuss TV series, football fans who gather to watch a match or avid users of a micro-blogging service commenting on an ongoing political discussion. In all three instances, media play a constitutive role for the communicative construction of a collectivity, either as conversation topics, as means of communication or both. Networked media collectivities can be densely knit or even be congruent to families, groups of friends, groups of work colleagues or other kinds of collectivities. However, they can also transcend these or may even construct detached collectivities and thereby lead to blurring of traditional social borders. Networked media collectivities can differ in size from small social groups to whole societies that follow a large media event and interact with reference to it, and stability (short and long lasting) which influences their visibility/observability. In cases of frequent and direct interaction, members of networked media collectivities may develop a strong identification with group membership. However, especially in ephemeral and larger collectivities, their 'members' may feel to be part of a collectivity, but may not even be aware of its exact boundaries and composition. The networks formed by those collectivities rapidly exceed the point where any actor can have a complete overview over their structure or identify their boundaries. With our concept of collectivities and our network analytic approach we draw also on Elias's idea of figurations that conceptualizes school classes, families, occupational groups or any other social aggregate as networks of individuals that are linked with each other in the most diverse ways' (1978: 15).

With respect to 'new' media as communication technologies, it is of great interest to find out how digital media affect current media and non-mediated communication. Several studies argue that there still is a strong relationship between face-to-face and online communication. Caughlin and Sharabi (2013) show that there is a positive correlation between the frequency of online and face-to-face communication. That is to say that online communication is most frequent with those persons we communicate with in person as well. The strong overlap of computermediated and face-to-face communication networks can at least partially be explained by the fact that new communication technologies are diffusing within the pre-existing social structures that are represented by face-to-face communication (Baym et al. 2004; Subrahmanyam et al. 
2008; Neuberger 2011; Reich et al. 2012; van Zalk et al. 2014). Offline relationships may not only be relevant for the adoption of new communication technologies. Latent tie theory assumes that offline relationships are also crucial for the maintenance of online communication (Haythornthwaite 2002, 2005). Digital communication technologies make it very low cost to socialize (van Zalk et al. 2014), to maintain or to reactivate old relationships (Ramirez and Bryant 2014), and some media seem to be typical for different social groups (Kim et al. 2007). But normally they remain weak ties (Granovetter 1973; Baym and Ledbetter 2009) that dissolve when the communication technologies lapse (Haythornthwaite 2005).

The relevance of media content as an object for everyday interpersonal communication is documented in various empirical studies. In fact, a substantial proportion of everyday conversations is related to mass media content (Friemel 2013; Keppler 2014; Weber 2015). For Germany, Kepplinger and Martin (1986) found in their observational study that $77 \%$ of all conversations in public places, bars and restaurants, at universities and in homes referred to media content. Since then, it has been pointed out that conversation topics have become more heterogeneous (differentiated) and media themselves have become more important as a conversation topic (Gehrau and Goertz 2010). Moreover, conversations about media content are able to fulfil important social functions (Friemel 2013). Media provide a constant source of conversation topics. Mass media content especially has the potential to serve as a ground of common knowledge from which conversations can arise (DiMaggio 1987; Friemel 2009). This can be a means to define inner structures and boundaries of collectivities. To display a shared preference for specific media content, to give an example, is one of several possibilities to express a sense of belonging and distinction from others (Hepp 1998). It has been shown that conversations surrounding mass media content can be an instrument to constitute hierarchy in relationships (Lull 1980). On a more general level, media content can also provide a starting point for the negotiation of norms and values in groups (Hurrelmann 1989) and in this way serve as one foundation for the construction of collectivities (Hepp et al. 2014). Conversations surrounding media content can thus be seen both as a means to facilitate the construction of media-based collectivities as well as a factor that mediatizes collectivities. 


\subsection{The Impact of Changing Media Environment on Social Capital}

Collectivities are important for their members as they provide access to various forms of resources and support. This is generally referred to as the concept of social capital, which is closely related to social network theory (Bourdieu 1983; Coleman 1988). Social capital can be defined as the resources that an actor is able to access or profit from because of his or her embeddedness in a social network (Lin 2001; Esser 2008). Well-known studies have shown the importance of social relationships for access to information when looking for a new job (Granovetter 1973; Marsden and Gorman 2001). However, the concept of social capital is not limited to the perspective of single actors. A whole collectivity can be researched as a social network to assess the resources brought to bear by its members as internal social capital (Lin 2008: 62f.). Other forms of a collectivity's social capital have been referred to as system capital. They are not directly accessed by actors through specific relationships, but can be seen as a feature of a specific collectivity itself. Examples range from the development of a climate of trust, to the adherence to and reinforcement of social norms, and the emergence of morality among a defined set of actors (Coleman 1988; Esser 2008).

In analogy to the general notion of mediatization and the idea of mediatized collectivities, we can assume that networked media collectivities are likely to become more prevalent in various types of social settings. In a nutshell, communication technologies make new means available to interconnect, and diversified media contents provide more topics for communication (the assumed consequences of optionality, social contingency and new chances for participation). Both play a crucial role in the establishment and maintenance of collectivities. The trends of a changing media environment mentioned in the introduction are assumed to affect the development and maintenance of various forms of collectivities and their social capital. At a first glance, the trend of differentiation of media as contents and technologies might lead to an erosion of traditional social structures. It has been argued that both weaken boundaries of families, groups or even whole societies. In a widely discussed work, Robert Putnam argued that the increase in consumption of mass media-particularly watching TV-led to a dramatic decline in various forms of civic engagement in US society (Putnam 2000). His empirical data show strong negative correlations between screen hours 
and attending public meetings, writing letters to Congress and being member or officer in a local organization. Similar effects are found for the relevance of TV for entertainment. Dependent on the relevance of TV as the primary form of entertainment, he found lower values for volunteering, writing letters to friends and relatives, attending club meetings, going to church and working on community projects. Putnam admits that the correlations reported cannot answer the question regarding the causal direction between TV use and the various forms of civic engagement. Nevertheless, based on other research such as the natural experiment on television reception in three Canadian communities in the 1970s (MacBeth 1986), he argues that the causal direction is likely to be directed from TV use towards civic and social life. Hence, according to Putnam, an increase of media use (e.g. TV), and especially the use of entertaining content (versus news and information) has a negative effect on various forms of collectivities.

The negative trend towards social isolation in the USA was supported by findings from the General Social Survey (GSS). McPherson and colleagues found that the core networks of US citizens decreased by about a third between 1985 and 2004, while the number of social isolates rose substantially (McPherson et al. 2006). This publication had a strong impact and is widely discussed in academia owing to its strong empirical foundation, since it is based on GSS data. However, subsequent methodological tests have revealed that the decrease is likely to be an effect of questionnaire design that made people name fewer persons (Marsden 2013) and an interviewer effect (Paik and Sanchagrin 2013). Furthermore, the finding of a decline is corroborated by almost no other evidence. Hence, no general decline in socializing since the 1970s can be found, apart from the downward trend in socializing with neighbours (Fischer 2011; Marsden and Srivastava 2012).

With a reference to technologies for interpersonal communication, Manuel Castells predicted fundamental changes for the organization of groups, social structures and societies as a whole (Castells 1996). Moreover, other authors assume that traditional groups and their structures are changing through the influence of the Internet. Boyd (2006) argues that on social networking sites every person is embedded in their very own egocentric network and the context of every person is different and only partially publicly visible. Wellman et al. describe a turn towards networked individualism which is driven by the Internet. It is described as a change from densely knit groups to sparsely knit networks (2003). 
In contrast to the negative connotation of Putnam's 'bowling alone', Rainie and Wellman (2012) come to a rather positive interpretation. They argue that nowadays an individual's main resource for social capital is to be found in each individual's personal relationships, which provide access to a wider range of contacts and thus more diverse resources. They therefore propose the term networked individualism as 'the new social operating system'.

\subsection{Research Questions}

Summarizing the previous paragraphs, we are facing theoretical and empirical arguments which suggest either a decay, a transformation or a renaissance of social patterns and collectivism in a networked society (Castells 1996, 2013; van Dijk 2006). The divergent interpretations can partly be explained by the different foci of the respective studies. While some offline activities seem to vanish, focusing on these leads to pessimistic conclusions. On the other hand, the Internet makes new forms of social support and civic engagement possible that draw a more positive picture of the societal changes related to the changing media environment. Therefore, the only valid approach to studying collectivities in a changing media environment is to study multiple relations simultaneously. Methodologically speaking, we have to collect multiplex network data (Wasserman and Faust 1994) in which multiple relations are taken into account and can be analyzed in relation to each other. In our case, these multiple relations can be various types of media technologies and different media content that people interact with (through these different media technologies). However, pushed to its extreme, this would result in a research design with an immense number of dimensions (number of media content $x$ number of communication technologies $x$ number of communication partners $x$ types of social support). We therefore decided to focus on the question of how communication about different media content is linked with friendship ties. Hence, differences in communication technologies are not considered and friendship is used as a proxy for social capital. For the empirical analysis of these hard-to-grasp collectivities, we investigate networked media collectivities among adolescents for two reasons: First, adolescents are known to have a more focused social network among their peers than is the case for other cohorts. For younger children, their parents are still a much more important point of reference. Adults are often simultaneously embedded 
in different social settings such as family, friends and workplace. Second, adolescents are usually among the early adopters when it comes to new communication technologies and services.

To investigate the figurations of networked media collectivities empirically, we have to address the communicative practices, the frames of relevance and the constellation of actors (Hepp and Hasebrink 2014). Hence, our first research question is RQI: What are the communicative practices of today's adolescents? Hereby, the communicative practices are operationalized as the frequency of use and the frequency of interpersonal communication about different mass media contents which are important to adolescents. This includes the question whether there is still enough shared interest in specific content even though media content has diversified.

Based on the results of these two kinds of communicative practices, we proceed to analyze the relationship between the two. With a reference to the concept of figuration, the second research question gives an insight into the frames of relevance. It is about the importance of different media content, to be able to communicate about them and thereby construct a networked media collectivity. RQ2: Are frequencies of mass media use and interpersonal communication about these contents correlated with each other?

The remaining constitutive feature of a communicative figuration is its actor constellation. This includes both the actors as well as the ties between them. In contrast to most of the previous research, we are not only interested to find out the type of persons the adolescents talk to (e.g. peers versus parents versus siblings versus teachers). Since we focus on the figurations among adolescents we are able to zoom into the actor constellation and reveal the actual network structure among all persons participating in our study. From the literature review in Sect. 8.2, it can be concluded that communication about media content provides a basis for stronger forms of social relationships. In Sect. 8.3, it was pointed out that they are the prerequisite for access to social capital. With our multiplex approach, we are able to disentangle the structural patterns of several overlapping collectivities before we assess their individual relevance for friendship in a later step. Our third research question therefore is RQ3: How frequently and within what actor constellation do people communicate about different media?

In addition to the individual analysis of communication about different media, we are interested in the relationship between these different 
networks of media use and media-related communication. How similar are the patterns of different actor constellations? Phrased in methodological terms, RQ4: What is the structural correlation of different communication networks?

Finally, we turn to the link between media use and social capital. To carve out the relationship between media use, media-related communication and friendship ties we include the friendship network in the same analysis as above. Again in methodological terms, RQ5: What is the structural correlation between communication networks and friendship networks?

Answering these five research questions allows us to empirically describe networked media collectivities with respect to different features that are constitutive for communicative figurations. Furthermore, we are able to answer the question concerning the relationship between networked media collectivities and access to social capital. Finally, this provides a good starting point to reflect on the potential consequences of deep mediatization for collectivities and our society.

\subsection{SAmple AND Methods}

The first aim of the present study is to describe the social domain of networked media collectivities as communicative figurations. Hence, it is necessary to extend the scope beyond that of individual attributes and take the actor constellations, communicative practices and frames of relevance into account that constitute these figurations. In order to do so, we apply a social network approach. Social network analysis is especially suitable to detect actor constellations and allows us to quantify how media collectivities coexist and interfere with each other.

The data were collected in three middle schools in a major German city (Bremen). As social network structures are of particular interest here, we sampled four grades in which all students were invited to participate in our survey. This includes two 10th grades as well as one 11 th and one 12th grade, respectively. The students and their parents were informed about the study in advance by letter and asked for written consent to participate. In total 335 students between 15 and 21 years of age participated in the survey $\left(53.2 \%\right.$ female, $M_{\mathrm{AGE}}=17.1$, $\left.\mathrm{SE}_{\mathrm{AGE}}=0.53\right)$. Data collection took place during class hours in the computer labs of the respective schools on a class-by-class basis. The 
students answered an online questionnaire (CASI) while a member of the project team was present.

The questionnaire consisted of questions regarding ownership and use of several technological media devices, use of specific media content such as TV programmes, YouTube channels and video games, and how often students engage in interpersonal communication about these contents. To measure social network structures several sociometric questions, socalled name generator questions, were asked. Name generator questions ask for other persons with whom a respondent is in a certain type of relationship. In this study, we gathered data on friendship ties and on interpersonal communication about TV programmes, YouTube channels and video games. These media were selected because they are among the most important for this age group with respect to usage and interpersonal communication. To get a comprehensive overview of the pattern of networked media collectivities, we allowed for cross-class nominations. Thus, for the social network analyses we have four different structures at hand for each school grade, that is to say the friendship network and three communication networks, one for each type of media content.

To answer research question RQ1, we applied frequency analyzes for six media types which are of special relevance for adolescents and the communication about these media. For RQ2, bivariate correlations between frequency of media use and conversation on the level of the students were calculated. Sociograms as a specific kind of visualization of social networks were used to answer RQ3 regarding actor constellations. Finally, to answer RQ4 and RQ5 regarding the structural correlation of communication networks and the friendship network, we performed Quadratic Assignment Procedure (QAP), which provides correlation statistics for social networks (Krackhardt 1987). The QAP can be used as a stochastical method to test whether two networks are significantly correlated, that is to say, for example, whether two students who talk about what they have seen on YouTube also tend to be friends or whether two students who talk about TV programmes also talk about video games, and so on.

\subsection{Media Use and Communication About Media CONTENT}

To be able to identify networked media collectivities as defined above, it is necessary to evaluate the relevance of several media in our sample. RQI addresses the communicative practices by means of frequencies of 


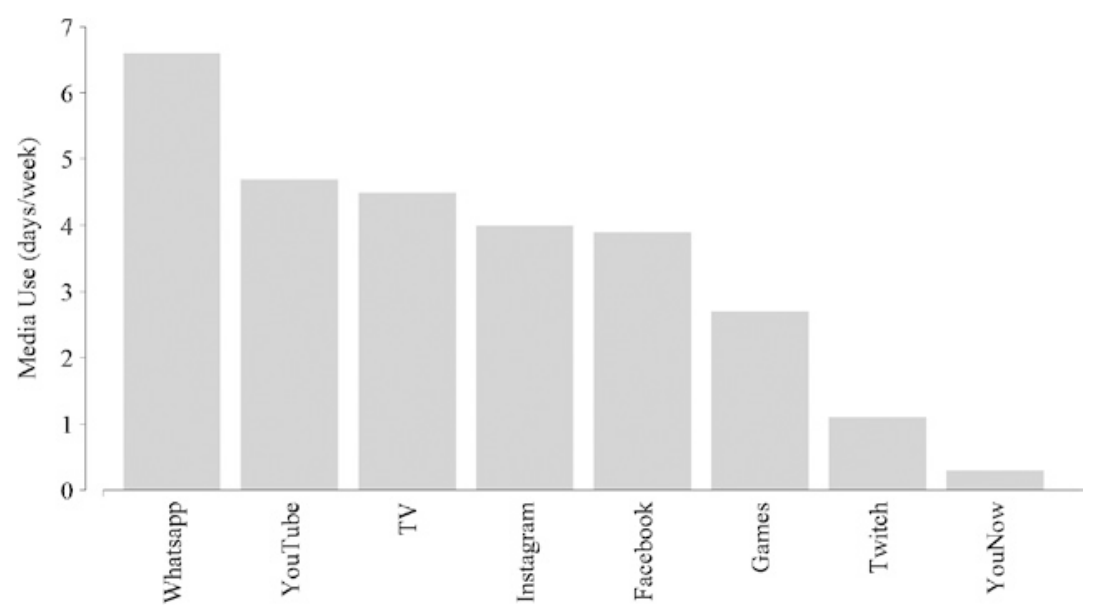

Fig. 8.1 Most frequently used media (days/week)

media use by adolescents. Figure 8.1 shows on how many days per week eight electronic media are used by the adolescents.

The media included were the most used screen-based media at the time of our survey. The set consists of one instant messenger service, several social media platforms and video sharing platforms as well as linear TV and video games. Results show that the instant messenger service Whatsapp was used most frequently of all media technologies. Most of our respondents reported using it every day or almost every day of a normal week $(M=6.6, \mathrm{SE}=0.08)$. When the survey was conducted, the installation of this application was not yet supported on desktop PCs, so a smartphone was necessary to use the service: $99.4 \%$ of our respondents indicated that they owned a mobile phone, $97.9 \%$ of whom owned a smartphone. Only two respondents out of four school grades reported that they did not own any kind of mobile phone. However, one of them explained in an open-ended question that his smartphone had been stolen only recently before the survey. These numbers are almost exactly in line with other representative studies in Germany (Feierabend et al. 2015).

In our sample, the video sharing platform YouTube was used slightly more often $(M=4.7, \mathrm{SE}=0.12)$ than linear TV $(M=4.5, \mathrm{SE}=0.14)$. Among social network sites, the picture and video sharing platform 
Instagram $(M=4.0, \mathrm{SE}=0.17)$ was slightly more frequently used than Facebook $(M=3.9, \mathrm{SE}=0.16)$. Our respondents indicated to play video games on 2.7 days per week on average $(S E=0.15)$. Further, the video streaming platforms Twitch $(M=1.1, \mathrm{SE}=0.14)$ and YouNow $(M=0.3, \mathrm{SE}=0.08)$ were used least often.

According to our definition of networked media collectivities, to speak of a collectivity it is not sufficient that the students use the same media. Our understanding requires a direct link among the actors. Only in collectivities in which actors can act and react upon each other are meanings and opinions negotiated and diffusion of information take place. Hence, a necessary requirement for these processes is that media content is the subject of interpersonal communication. To assess the importance of media content in interpersonal communication, we asked our respondents to indicate how frequently they talk about their most-used media on a five point scale. We also included 'school exams' as a conversation topic to have a point of reference for other important everyday matters. Figure 8.2 shows the results. School exams were the topic that was most frequently discussed at the time of our survey $(M=3.6, \mathrm{SE}=0.05)$. Almost as frequent was communication about content sent via the instant messenger service Whatsapp $(M=3.5, \mathrm{SE}=0.07)$. Despite some differences in frequency of use, all other types of media content were about equally often the

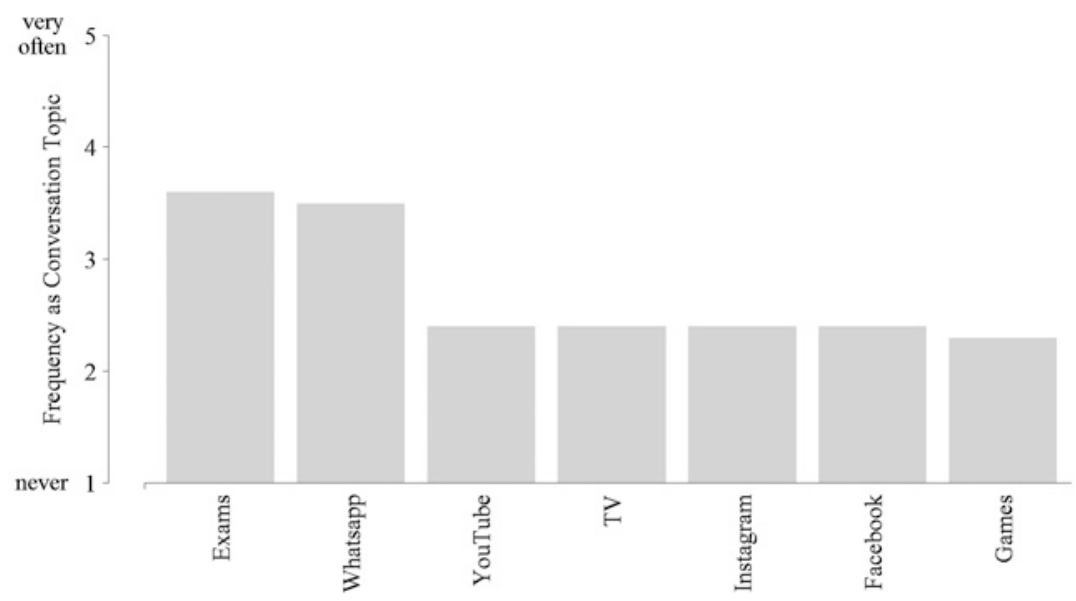

Fig. 8.2 Most frequent conversation topics 
subject of interpersonal communication (YouTube: $M=2.4, \mathrm{SE}=0.06$, TV: $M=2.4, \mathrm{SE}=0.06$, Instagram: $M=2.4, \mathrm{SE}=0.08$, Facebook: $M=2.4, \mathrm{SE}=0.07$, Video games: $M=2.3, \mathrm{SE}=0.08$ ). These data show that despite the general trend towards a diversified media content, people still have enough in common to be able to talk about a topic. Whether this is because they have used the same content or another function of interpersonal communication about mass media content (Friemel 2013 ) is of relevance cannot be answered by this data.

A comparison between the frequencies of media use and the frequencies of media-related interpersonal communication for each of the media shows that Whatsapp stands out as a communication technology as well as a source for conversation topics. All other media differ mainly in frequency of use, but not in their ability to provide conversation topics. Nevertheless, the communicative practices regarding all included media seem to meet our criteria to be constitutive for a communicative figuration of networked media collectivities. Hence, it will be of interest to further characterize these figurations. We will do so by answering the next three research questions (RQ2-RQ4).

$R Q 2$ goes a step further by addressing the correlation between media use and communication about media content. As can be expected, bivariate correlation (Table 8.1) shows that the frequencies of use and the frequencies of media-related communication are positively correlated with substantial effect sizes for each media type (grey-coloured cells). The strongest correlation is found for games. The value of $r=0.78$ means that the frequency of gaming and game-related communication is very strongly correlated. The more someone plays computer games the more this person also talks about it (and vice versa). At the same time, TV use and TV-related communication are only moderately correlated. Hence, while TV is among the most frequently used media to be used, interpersonal communication on the topic is not so closely linked as for the other media types. However, it has to be taken into account that this finding is limited to the level of frequency. Therefore, we cannot rule out that there are specific genres or even single TV programmes which are closer linked to interpersonal communication (Friemel 2012, 2015). With respect to RQ2, we can conclude that the frequencies of mass media use and interpersonal communication about these contents are indeed correlated with each other, and for most media this correlation is rather strong. Almost all of the other parameters in the top right quadrant of Table 8.1 are non-significant or negatively correlated. Hence, beside the 


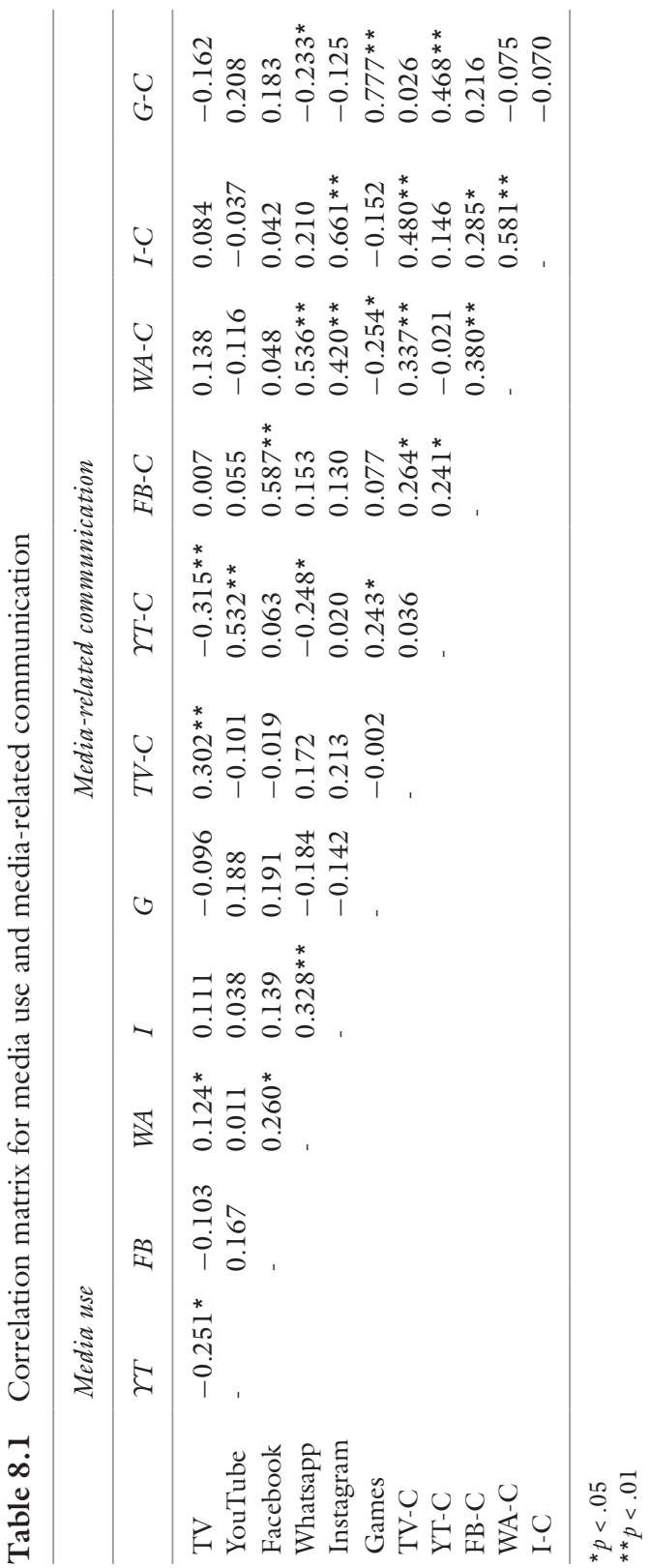


correlation between the frequencies of Instagram use and Whatsapprelated communication, the communicative practices of the various media seem to be independent from one another.

The top left quadrant of the matrix reveals patterns of media use by means of indicating whether the frequency of use is correlated with the use of other media types. It is found that only instant messenger and social media services - which are mainly designed as means for interpersonal communication-can be regarded as a bundle of media that are used in combination and thereby form a common media repertoire (Hasebrink and Domeyer 2012). In addition, we find also negative relations between frequencies of media use. Results show that TV and YouTube tend to be negatively associated, which can be interpreted as an indicator for substitution of one by the other.

Likewise, we can also focus on how communication about various media is related (bottom right quadrant). There are several media which seem to be often talked about by the same people, but also some that seem to be mutually exclusive. Again, Facebook, Whatsapp and Instagram form a bundle of conversation topics. For YouTube-related communication, positive correlations are found for Facebook and game-related communication. Both are highly plausible, since a substantial share of the most popular YouTube channels are about gaming and Facebook is a common platform to share YouTube videos.

Besides answering RQ2 with a clear yes (correlations between media use and communication about these media), the data reveal a complex constellation of communicative practices. While the correlation values reported here provide an overall indicator for communicative practices, they neglect the actor constellation in which these practices take place. We now turn to social network analytic approaches to identify networked media collectivities.

\subsection{Networks of Media-Related Communication}

In this section we look at actor constellations emerging from communication about media content to identify networked media collectivities and thus answer RQ3 (How frequent and within what actor constellation do people communicate about different media?). In doing so, we compare structural patterns for different media types as well as with the underlying actor constellation of the friendship network. This allow us to answer in a next step RQ4 and RQ5 by testing to which extent networked media collectivities emerge across different media types and whether they are linked to social capital (RQ4 and RQ5). 
Table 8.2 Network descriptives by school grade

\begin{tabular}{|c|c|c|c|c|c|c|c|c|c|c|c|c|}
\hline & \multicolumn{3}{|c|}{$\begin{array}{l}\text { School grade A } \\
\text { (10th) }\end{array}$} & \multicolumn{3}{|c|}{$\begin{array}{l}\text { School grade B } \\
\text { (10th) }\end{array}$} & \multicolumn{3}{|c|}{$\begin{array}{l}\text { School grade C } \\
\text { (11th) }\end{array}$} & \multicolumn{3}{|c|}{$\begin{array}{l}\text { School grade D } \\
(12 t h)\end{array}$} \\
\hline & $\begin{array}{l}D \\
(\%)\end{array}$ & $M$ & $S E$ & $\begin{array}{l}D \\
(\%)\end{array}$ & $M$ & $S E$ & $\begin{array}{l}D \\
(\%)\end{array}$ & $M$ & $S E$ & $\begin{array}{l}D \\
(\%)\end{array}$ & $M$ & $S E$ \\
\hline Friendship & 5.1 & 4.10 & 0.33 & 6.7 & 5.89 & 0.34 & 4.2 & 4.74 & 0.28 & 4.2 & 5.54 & 0.30 \\
\hline $\begin{array}{l}\text { TV com- } \\
\text { munica- } \\
\text { tion }\end{array}$ & 1.7 & 1.39 & 0.17 & 1.9 & 1.67 & 0.15 & 1.4 & 1.65 & 0.14 & 1.4 & 1.89 & 0.17 \\
\hline $\begin{array}{l}\text { YouTube } \\
\text { communi- } \\
\text { cation }\end{array}$ & 1.6 & 1.26 & 0.16 & 1.7 & 1.53 & 0.18 & 0.3 & 1.40 & 0.13 & 1.2 & 0.41 & 0.08 \\
\hline $\begin{array}{l}\text { Video } \\
\text { game com- } \\
\text { munica- } \\
\text { tion }\end{array}$ & 1.2 & 1.00 & 0.16 & 1.8 & 1.56 & 0.23 & 0.7 & 1.08 & 0.17 & 0.9 & 0.97 & 0.14 \\
\hline
\end{tabular}

Since networked media collectivities require direct ties among the actors, we analyze the four grades' levels as separate actor constellations. In each grade level, three communication networks and a friendship network were collected (see Sect. 8.5). Table 8.2 gives the network density and the mean number of ties for each network from each school grade. The school grades are in ascending order and labelled A, B, C and D. Network density $(D)$ is defined as the proportion of existing ties in a network in relation to the maximum number of possible ties. The friendship network of school grade B, for example, has a density of $6.7 \%$, which means that almost $7 \%$ of all possible friendship ties were present at the time of the survey. Given the size of the networks (89-132 students per grade level), this is a reasonable value. In addition, the average number of ties per actor for each of the networks is given $(M)$ as well as corresponding standard errors (SE).

Results show that in all four grade levels the density of the friendship networks is substantially higher than for the communication networks. In fact, it is at least three times the density of each of the communication networks in the same school grade. Comparing the three communication networks over all grade levels, it can be seen that the communication networks on TV content have the highest density. This 
might surprise since the frequency in which students talk about the three media (Fig. 8.2) is almost equal. Hence, our network analytic measures provide a more granular insight that is not possible based on a frequency scale. An alternative explanation could be that communication about YouTube and video games is less bound to the school context than communication about TV.

Sociograms enable us to assess how frequently and within what actor constellation people communicate about different media (RQ3). Figures 8.3, $8.4,8.5,8.6$ show the sociograms of all four networks from school grade

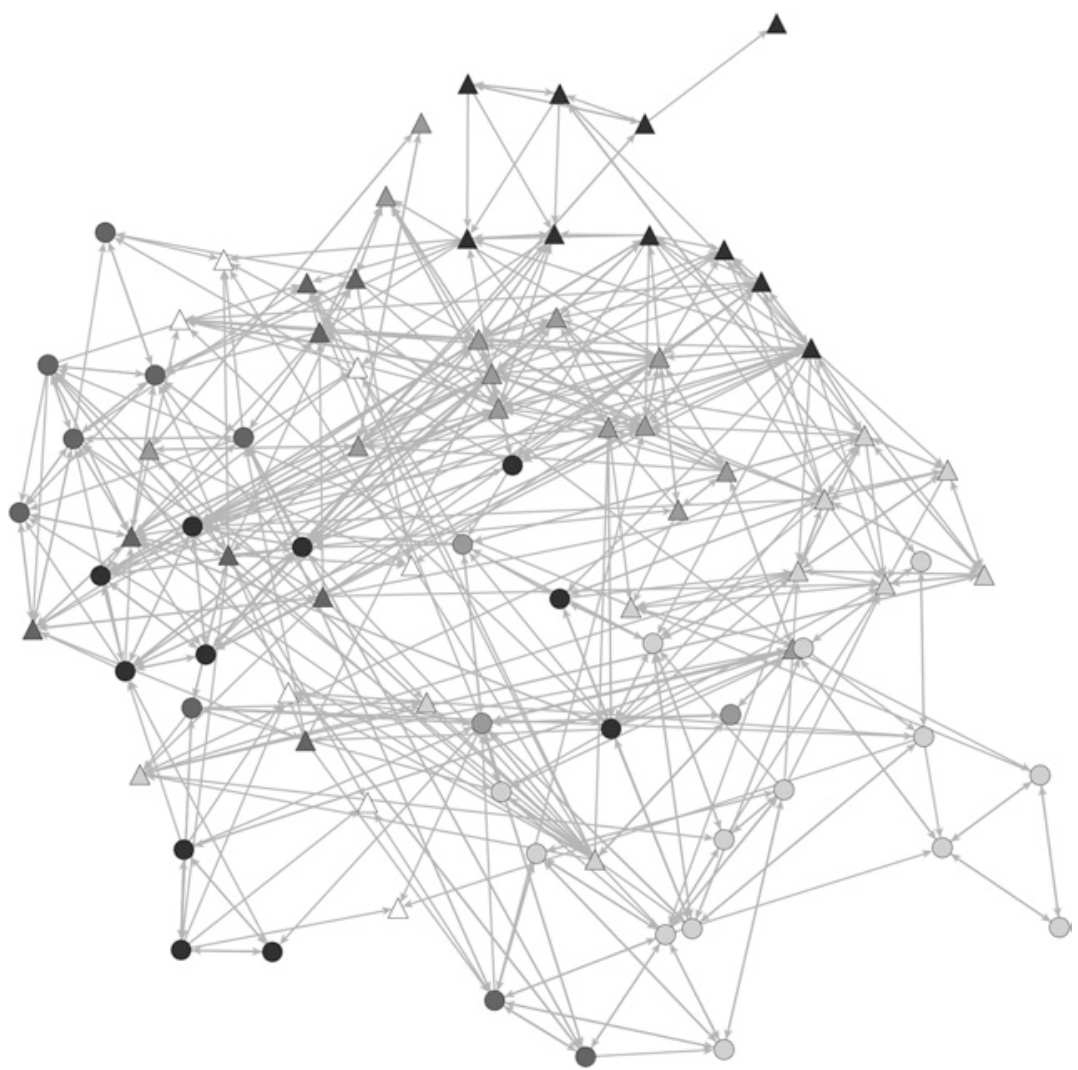

Fig. 8.3 School grade B friendship. Triangles male; circle female; greyscale class membership; tie friendship nomination 


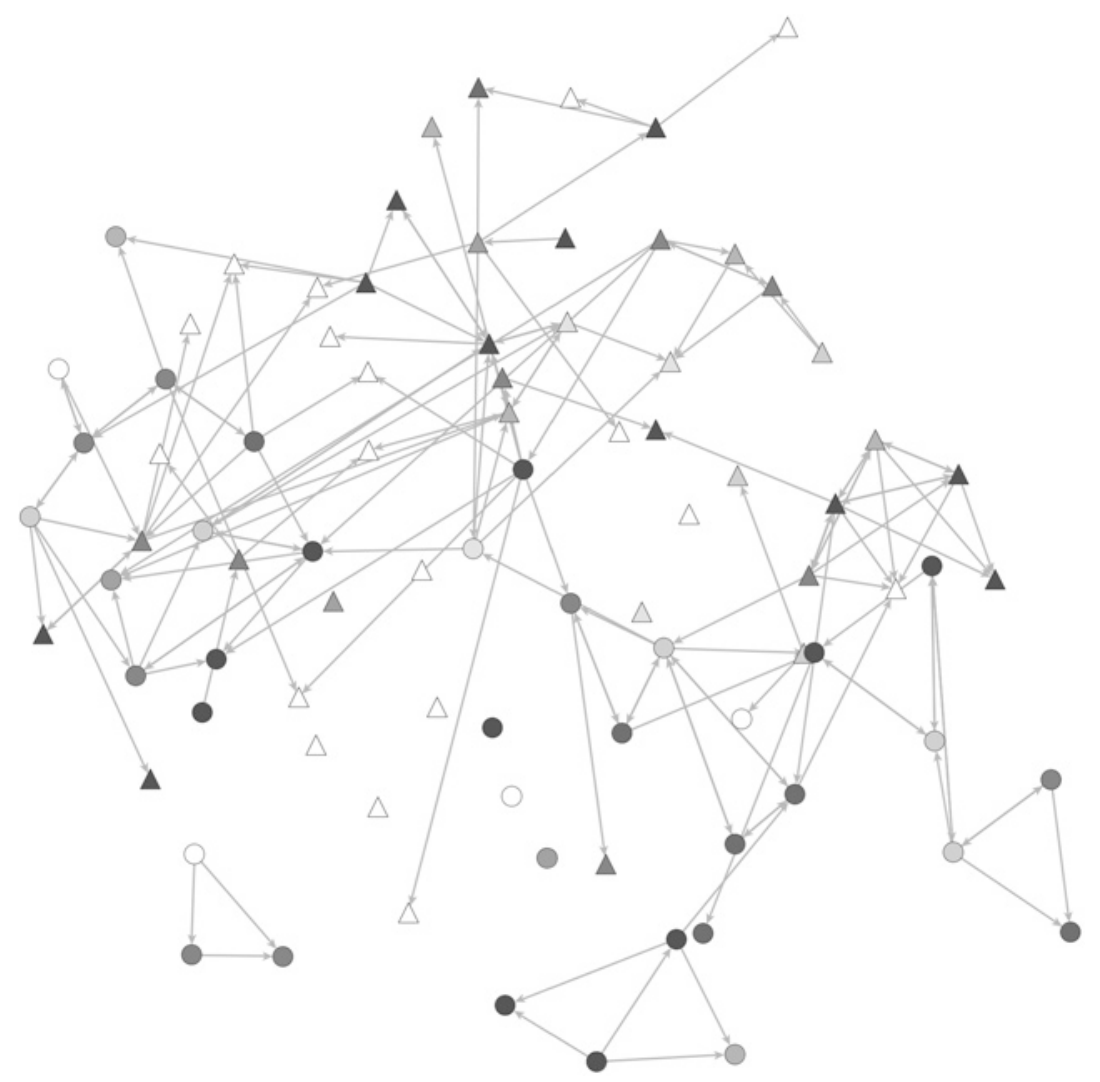

Fig. 8.4 School grade B TV communication. Triangles male; circle female; greyscale intensity frequency of TV use; tie interpersonal communication about TV

B. Each node represents one student, whereas triangles stand for male students and circles for female students. An edge indicates a tie between two students (i.e. friendship or conversation tie). The positioning of the nodes is fixed over all visualizations to facilitate comparison. Figure 8.3 shows the friendship network for school grade B. Classroom membership is indicated by different shades of grey. The way they are distributed over the graph suggests that a substantial proportion of friendship ties occur within classrooms, but there is also a considerable amount of cross-class nominations. Hence, this supports the chosen research design that was not bound to 


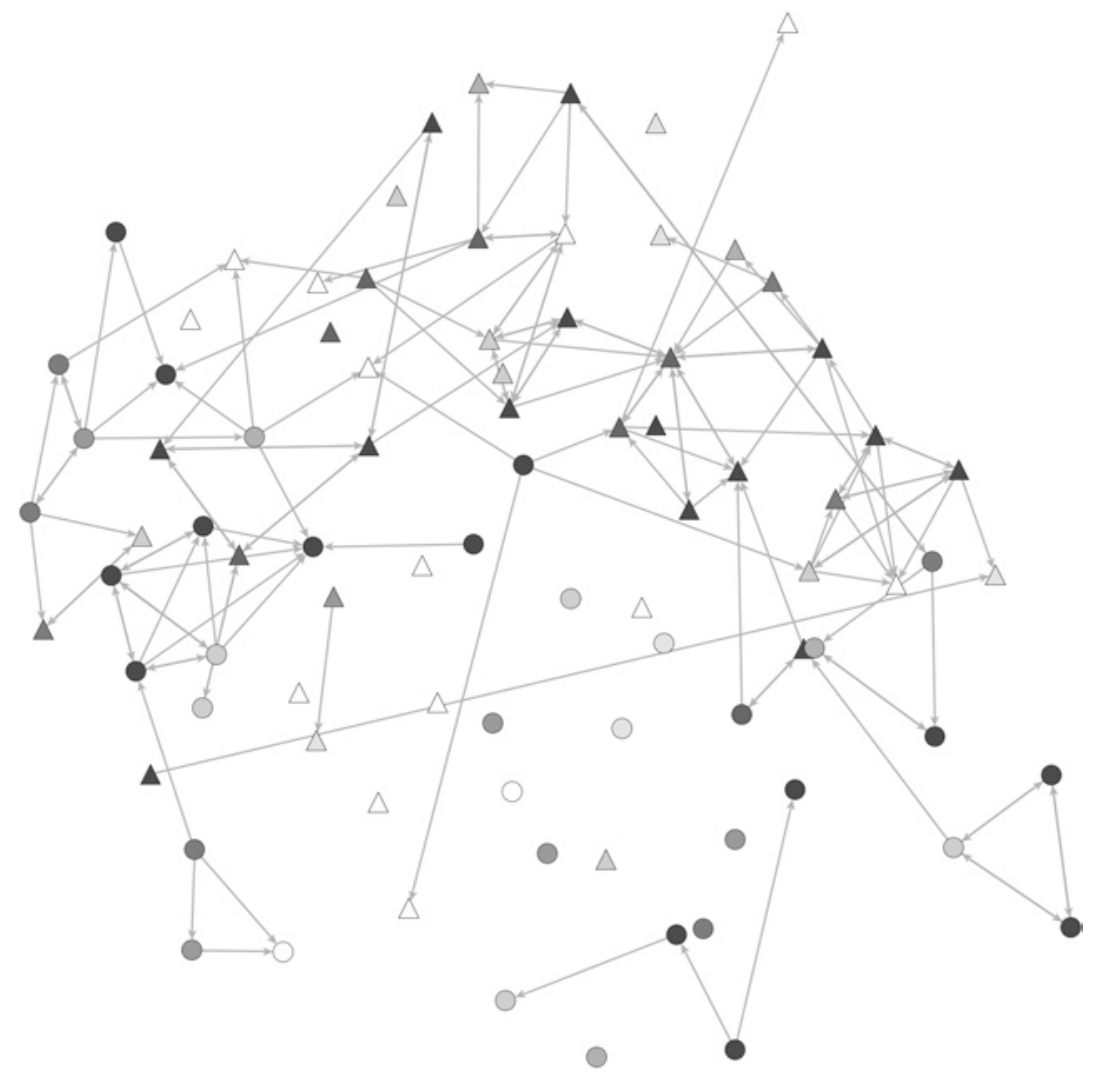

Fig. 8.5 School grade B YouTube communication. Triangles male; circle female; greyscale intensity frequency of YouTube use; tie interpersonal communication about YouTube

classrooms but included entire grade levels (Friemel and Knecht 2009). Denser parts of the network suggest the existence of cliques of friends. Figures 8.4, 8.5, 8.6 show the respective networks for communication about TV, YouTube and video games. In these networks, the intensity of the greyscale indicates the frequency of use of the medium in question; for example, the darker a node in Fig. 8.4 the more frequently that person watches TV. A visual exploration of each of these communication networks supports the results from correlation analysis above (cf. Table 8.2). In all three networks, darker coloured nodes tend to be linked by more 


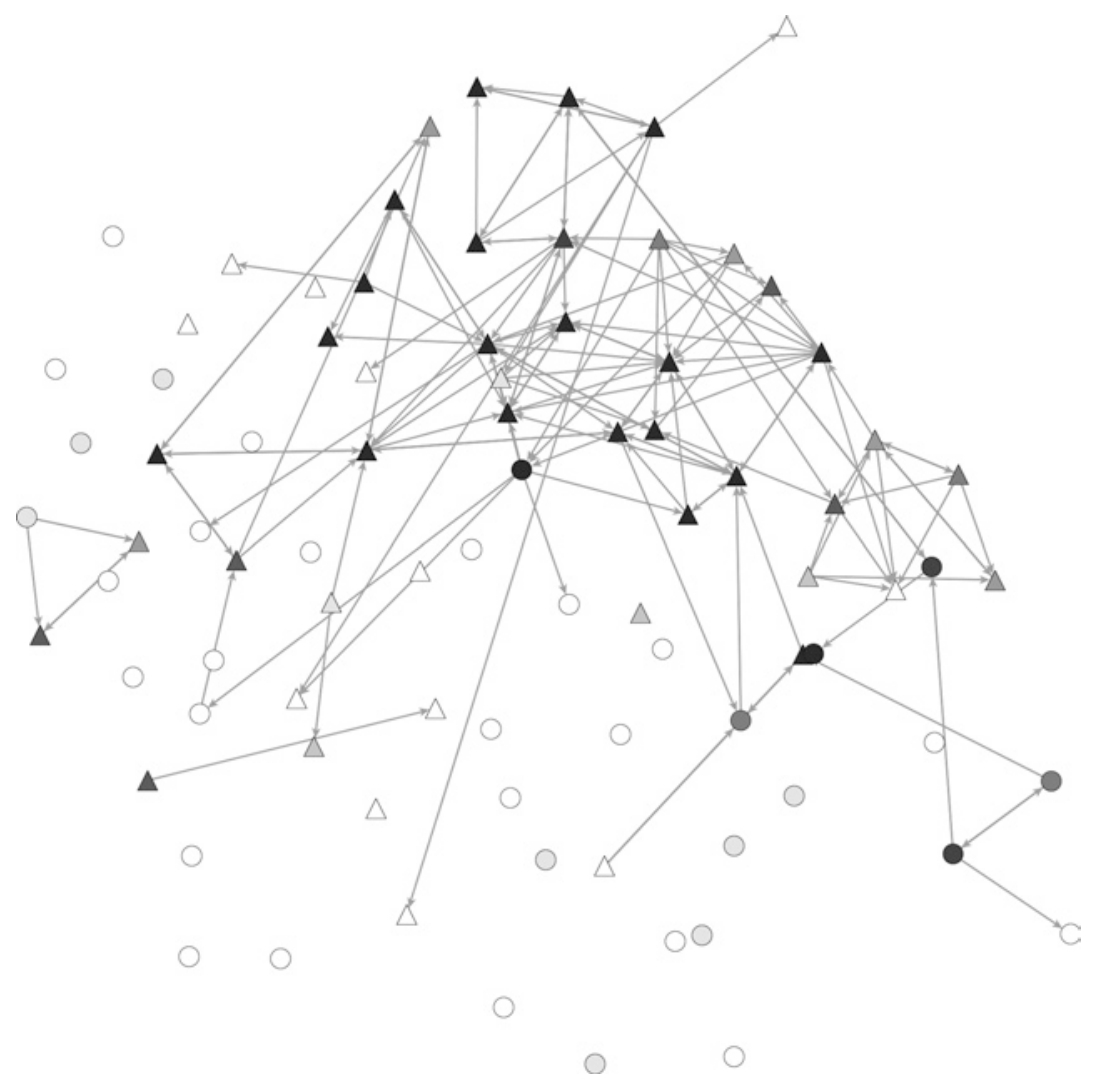

Fig. 8.6 School grade B gaming communication. Triangles male; circle female; greyscale intensity frequency of video game use; tie interpersonal communication about video games

ties to other nodes. Light-coloured nodes tend to be weakly connected or even isolated from the rest of the network. This is most striking in Figs. 8.5 (YouTube communication) and 8.6 (video game communication). Furthermore, the clustering of ties in certain parts of the communication networks and their absence in others indicates that communication about media content often takes place among groups of friends. Finally, some regions of the graphs show similar actor constellations for two or more media types, resulting in multiplex relationships in collectivities. 
Table 8.3 QAP correlations by school grade

\begin{tabular}{lllll}
\hline School grade A & $T V-C$ & YT-C & $G-C$ & Multiplex communication \\
Friendship & $0.373^{* * *}$ & $0.456^{* * *}$ & $0.459^{* * *}$ & $0.576^{* * *}$ \\
TV communication & - & $0.369^{* * *}$ & $0.606^{* * *}$ & \\
YouTube communication & & - & $0.464^{* * *}$ & \\
Games communication & & & - & \\
School grade B & $T V$ & $r T$ & $G$ & Multiplex communication \\
Friendship & $0.354^{* * *}$ & $0.396^{* * *}$ & $0.429 * * *$ & $0.508^{* * *}$ \\
TV communication & - & $0.371^{* * *}$ & $0.515^{* * *}$ & \\
YouTube communication & & - & $0.464^{* * *}$ & \\
Games communication & & & - & \\
School grade C & $T V$ & $r T$ & $G$ & Multiplex communication \\
Friendship & $0.327^{* * *}$ & $0.513^{* * *}$ & $0.469^{* * *}$ & $0.580^{* * *}$ \\
TV communication & - & $0.267^{* * *}$ & $0.411^{* * *}$ & \\
YouTube communication & & - & $0.505^{* * *}$ & \\
Games communication & & & - & \\
School grade D & $T V$ & $r T$ & $G$ & Multiplex communication \\
Friendship & $0.320^{* * *}$ & $0.491^{* * *}$ & $0.240^{* * *}$ & $0.541^{* * *}$ \\
TV communication & - & $0.294^{* * *}$ & $0.212^{* * *}$ & \\
YouTube communication & & - & $0.253^{* * *}$ & \\
Games communication & & & - &
\end{tabular}

$* * * p<0.001$

Similar patterns can be found for grade levels A, C and D that are not visualized here. With respect to RQ3, we can conclude that networked media collectivities show the same general pattern as are found for other mediarelated social networks (Friemel 2012, 2015; Shoham et al. 2012; Steglich et al. 2006). First, media use serves as a resource to create and maintain social ties. Second, this leads to a pattern of network auto-correlation in which actors of similar media use tend to be stronger linked than other actors.

RQ4 regarding the structural correlation of different communication networks can be answered by computing correlation coefficients and estimated significance values with QAP. Table 8.3 shows the results for these correlations between all networks within each school grade. They can be interpreted in the same ways as the bivariate correlations in Table 8.1. For all school grades, we find positive and significant correlations between all networks and RQ4 can be answered with a clear yes (there is substantial structural correlation). However, effect sizes are varying. Except for school grade D, they seem to follow a certain pattern, in which the correlation between the TV and YouTube network is the lowest of all communication networks. For example the networks regarding 
TV and video games are more similar than the TV and YouTube networks. Even though this finding might be surprising at first, this is consistent with the findings reported in Table 8.1 (negative correlation between YouTube and TV use and positive correlation between YouTube and game-related communication). Only in school grade D are correlations in general rather weak. All differences between the correlation coefficients are significant at the $1 \%$ level. In sum, we can conclude that networked media collectivities are transcending different media types by ascertaining that actor constellations are somewhat similar across TV, YouTube and game-related interpersonal communication.

Finally, we turn to RQ5 to answer whether there is a structural correlation between communication and friendship networks. This is of relevance since friendship ties are an important source for various kinds of support and thus are a proxy for the social capital of and within collectivities. The analytic approach of calculating QAP correlations is the same as for RQ4. Again, we find positive and highly significant correlations between each of the media-related communication networks and the friendship network. All school grades but school grade D follow a similar pattern, in that communication about TV content shows the lowest overlap with the friendship network. In addition, we calculated the overlap of the friendship network with the multiplex network of all three media-related communication. Here, even higher correlations are found than for the individual communication networks, indicating that the friendship network is most similar with a multiplex operationalization of networked media collectivities. This supports our theoretical and empirical approach that builds on the idea of a figuration as a combination of multiple networks of interpersonal communication, friendship and media use.

\subsection{Current Findings and Future Research on Networked Media Collectivities}

We started our contribution with a two-sided perspective of how media are related to the communicative construction of collectivities. First, they serve as technologies to bypass time and space. Second, media provide content for various forms of interpersonal communication. Based on this distinction and the literature on media use in social contexts, we subsequently developed the concept of networked media collectivities. These are defined as networked sets of actors with shared communicative practices. We furthermore emphasized the necessity of direct links between 
the individuals, since the concept otherwise would be a synonym for the audience of media content or all users of a media technology. The idea of networked media collectivities is linked to the literature on social capital. We therefore summarized the theoretically assumed and empirically identified impact of a changing media environment on social capital. In sum, this includes both arguments for an increase of social capital, as well as a decline. However, the unidirectional perspective of how a changing media environment influences social structures is short sighted in that it is rather a mutual dependency. It is likely that the social context also has an influence on media use and media-related communication.

Based on these lines of reasoning, we developed five research questions to investigate the figurations of networked media collectivities and tested them based on networks of four German school grades encompassing 335 students. The research questions address the three defining features of a communicative figuration: the communicative practices, the frames of relevance and the constellation of actors.

RQ1 concerned the communicative practices of today's adolescents. Our results show that the instant messaging service Whatsapp is used nearly every day by most of the participants. Whatsapp and related issues were also the topic adolescents talked most about in person. YouTube, TV, Instagram, Facebook and video games were both less used and talked about. Based on these data, it was also tested whether frequencies of mass media use and interpersonal communication about these contents are correlated with each other and therefore define a frame of relevance for adolescents (RQ2). The respective results show that media use and media-related communication are strongly correlated on the level of the various media types. Hence, this supports the general idea that media use provides sources for interpersonal communication. Finally, we addressed the actor constellation of the communicative figuration by analyzing the friendship networks and the networks of interpersonal communication about TV, YouTube and gaming (RQ3), the structural correlation among the communication networks (RQ4) and their correlation with the friendship network (RQ5). The friendship network hereby serves as a proxy for social capital. The respective results show that media in fact seem to serve as a resource to create and maintain social ties, since people with a similar intensity of media use are more likely to communicate about the respective media compared to dissimilar others. This is also supported by the findings regarding the positive structural correlation between the different networks (RQ4). This finding supports our assumption that the figuration of networked media collectivities should be 
understood as a combination of multiple (partially overlapping) networks. The findings regarding RQ5 finally show that these media-related communication networks are strongly related to the friendship network.

These findings suggest multiple conclusions. First, networked media collectivities should not be limited to a single medium. The structures transcend various types, but every network also has its own characteristics that help to reach a holistic representation of the figurations. Second, networked media collectivities are likely to be a resource of social capital. Media-related conversations are found to be of substantial relevance for everyday interaction and can be assumed to help create and maintain social ties. In fact, we are able to show strong overlap between media-related communication networks and friendship structures. Third, if figurations of friendship networks among adolescents are regarded as a benchmark for what structural properties a figuration should have, we are able to validate our theoretical and empirical approach of networked media collectivities.

The proposed concept of networked media collectivities seems to provide an appropriate theoretical and methodological approach to describe today's media use of adolescents and its interdependence with social structures. However, only a longitudinal extension of this research design will be able to test how the changing media environment alters processes and characteristics of networked media collectivities. Hence, the consequences of the four trends described in the introduction (connectivity, omnipresence, differentiation, datafication) need to be analyzed in future studies.

\section{REFERENCES}

Baym, Nancy. 2015. Personal connections in the digital age. Cambridge: Polity Press.

Baym, Nancy, and Andrew Ledbetter. 2009. Tunes that bind? Information, Communication \& Society 12 (3): 408-427.

Baym, Nancy, Yan B. Zhang, and Mei-Chen Lin. 2004. Social interactions across media: Interpersonal communication on the Internet, telephone and face-toface. New Media \& Society 6 (3): 299-318.

Bourdieu, Pierre. 1983. Ökonomisches Kapital, kulturelles Kapital, soziales Kapital. In Soziale Ungleichheiten, ed. Reinhard Kreckel, 183-198. Göttingen: Schwartz.

Boyd, Danah. 2006. Friends, friendsters, and MySpace Top 8. Writing community into being on social network sites. First Monday 11 (12). http://firstmonday. org/ojs/index.php/fm/article/view/1418/1336. Accessed 30 Mar 2017.

Castells, Manuel. 1996. The information age. The rise of the network society. Oxford: Blackwell. 
Castells, Manuel. 2013. Communication power. Oxford: Oxford University Press.

Caughlin, John P., and Liesel L. Sharabi. 2013. A communicative interdependence perspective of close relationships: The connections between mediated and unmediated interactions matter. Journal of Communication 63 (5): 873-893.

Coleman, James S. 1988. Social capital in the creation of human capital. The American Journal of Sociology 94: 95-120.

Couldry, Nick, and Andreas Hepp. 2017. The mediated construction of reality. Cambridge: Polity Press.

DiMaggio, Paul. 1987. Classification in art. American Sociological Review 52 (4): $440-455$.

DIVSI. 2014. DIVSI U25-Studie. Kinder, Jugendliche und junge Erwachsene in der digitalen Welt [Survey Children, teenagers and young adults in the digital world]. https://www.divsi.de/wp-content/uploads/2014/02/DIVSI-U25Studie.pdf. Accessed 30 Mar 2017.

Elias, Norbert. 1978. What is sociology? New York: Columbia University Press.

Erickson, Bonnie. 2003. Social networks. The value of variety. Contexts 2 (1): 25-31.

Esser, Hartmut. 2008. The two meanings of social capital. In The handbook of social capital, ed. Dario Castiglione, Jan W. van Deth, and Guglielmo Wolleb, 22-49. Oxford: Oxford University Press.

Esser, Frank, and Jesper Strömbäck. 2014. Mediatization of politics. Houndmills: Palgrave.

Feierabend, Sabine, Theresa Plankenhorn, and Thomas Rathgeb. 2015. JIM 2012. Jugend, information. (Multi-) media. Basisstudie zum Medienumgang 12- bis 19-Jähriger in Deutschland. Stuttgart: mpfs.

Fischer, Claude S. 2011. Still connected: Family and friends in America since 1970. New York: Russell Sage Foundation.

Friemel, Thomas N. 2009. Mediensport als Gesprächsthema. Sozialpsychologische Betrachtung der interpersonalen Kommunikation über Sportberichterstattung in Massenmedien [Media sport as conversation topic. A social-psychological perspective on interpersonal communication about sport coverage in mass media]. In Die Sozialpsychologie des Sports in den Medien, eds. Holger Schramm and Mirko Marr, 199-222. Köln: Halem.

Friemel, Thomas N. 2012. Network dynamics of television use in school classes. Social Networks 34 (2): 346-358.

Friemel, Thomas. N. 2013. Sozialpsychologie der Mediennutzung. Konstanz: UVK.

Friemel, Thomas N. 2015. Influence vs. selection: A network perspective on opinion leadership. International Journal of Communication 1002-1022. http://ijoc.org/index.php/ijoc/article/view/2806. Accessed 30 Mar 2017.

Friemel, Thomas N., and Andrea Knecht. 2009. Praktische Grenzen vs. effektive Netzwerke. In Netzwerkgrenzen, eds. Christian Stegbauer and Roger Häußling, 15-32. Wiesbaden: VS. 
Gehrau, Volker, and Lutz Goertz. 2010. Gespräche über Medien unter veränderten medialen Bedingungen. Publizistik 55 (2): 153-172.

Granovetter, Mark S. 1973. The strength of weak ties. The American Journal of Sociology 78 (6): 1360-1380.

Grunig, James E., and Keith R. Stamm. 1973. Communication and coorientation of collectives. American Behavioral Scientist 16 (4): 567-591.

Gruzd, Anatoliy, Barry Wellman, and Yuri Takhteyev. 2011. Imagining Twitter as an imagined community. American Behavioral Scientist 55 (10): 1294-1318.

Hasebrink, Uwe, and Hanna Domeyer. 2012. Media repertoires as patterns of behaviour and as meaningful practices: A multimethod approach to media use in converging media environments. Participations 9 (2): 757-783.

Haythornthwaite, Caroline. 2002. Strong, weak, and latent ties and the impact of new media. The Information Society 18 (5): 385-401.

Haythornthwaite, Caroline. 2005. Social networks and Internet connectivity effects. Information, Communication \& Society 8 (2): 125-147.

Hepp, Andreas. 1998. Fernsehaneignung und Alltagsgespräche. Fernsehnutzung aus der Perspektive der Cultural Studies. Opladen: Westdeutscher Verlag.

Hepp, Andreas, Matthias Berg, and Cindy Roitsch. 2014. Mediatisierte Welten der Vergemeinschaftung. Kommunikative Vernetzung und das Gemeinschaftsleben junger Menschen. Wiesbaden: Springer VS.

Hepp, Andreas, and Uwe Hasebrink. 2014. Human interaction and communicative figurations: The transformation of mediatized cultures and societies. In Mediatization of communication, ed. Knut Lundby, 249-272. Berlin and New York: de Gruyter.

Hurrelmann, Bettina. 1989. Fernsehen in der Familie. Weinheim and München: Juventa.

Jensen, Klaus B. 2010. Media convergence. London and New York: Routledge.

Keppler, Angela. 2014. Reichweiten alltäglicher Gespräche. In Unser Alltag ist voll von Gesellschaft, ed. Alfred Bellebaum and Robert Hettlage, 85-104. Wiesbaden: VS.

Kepplinger, Hans-Martin, and Verena Martin. 1986. Die Funktionen der Massenmedien in der Alltagskommunikation. Publizistik 31 (1-2): 118-128.

Kim, Hyo, Gwang J. Kim, Han W. Park, and Ronald E. Rice. 2007. Configurations of relationships in different media: FtF, email, instant messenger, mobile phone, and SMS. Journal of Computer-Mediated Communication 12 (4): 1183-1207.

Krackhardt, David. 1987. QAP partialling as a test of spuriousness. Social Networks 9 (2): 171-186.

Lin, Nan. 2001. Social capital. A theory of social structure and action. New York: Cambridge University Press.

Lin, Nan. 2008. A network theory of social capital. In The handbook of social capital, ed. Dario Castiglione, Jan W. van Deth, and Guglielmo Wolleb, 50-69. Oxford: Oxford University Press. 
Lull, James. 1980. The social uses of television. Human Communication Research 6 (3): 197-209.

Lundby, Knut. 2014. Mediatization of communication. Berlin and New York: de Gruyter.

MacBeth, Tannis M. 1986. The impact of television: A natural experiment in three communities. Orlando, FL: Academic Press.

Marsden, Peter V. 2013. An experiment about questionnaire context effects on name generator data. Invited presentation at ARS '13 fourth international workshop, "Networks in Space and Time: Models, Data Collection and Applications”, Rome, Italy, June, 2013.

Marsden, Peter V., and Elizabeth H. Gorman. 2001. Social networks, job changes, and recruitment. In Sourcebook on labor markets. Evolving structures and processes, eds. Ivar Berg and Arne L. Kalleberg, 476-502. New York: Kluwer Academic/Plenum.

Marsden, Peter V., and Sameer B. Srivastava. 2012. Trends in informal social participation, 1974-2008. In Social trends in American life: Findings from the general social survey since 1972, ed. Peter V. Marsden, 240-263. Princeton, NJ: Princeton University Press.

McPherson, Miller, Lynn Smith-Lovin, and Matthew E. Brashears. 2006. Social isolation in America: Changes in core discussion networks over two decades. American Sociological Review 71: 353-375.

Neuberger, Christoph. 2011. Soziale Netzwerke im Internet. Kommunikationswissenschaftliche Einordnung und Forschungsüberblick. In StudiVZ. Diffusion, Nutzung und Wirkung eines sozialen Netzwerks im Internet, eds. Volker Gehrau and Christoph Neuberger, 33-96. Wiesbaden: Springer VS.

Paik, Anthony, and Kenneth Sanchagrin. 2013. Social isolation in America: An artifact. American Sociological Review 78: 339-360.

Putnam, Robert D. 2000. Bowling alone. The collapse and revival of American community. New York: Simon \& Schuster.

Rainie, Lee, and Barry Wellman. 2012. Networked. The new social operating system. Cambridge, MA: MIT Press.

Ramirez, Artemio, and Erin M. Bryant. 2014. Relational reconnection on social network sites: An examination of relationship persistence and modality switching. Communication Reports 27 (1): 1-12.

Reich, Stephanie M., Kaveri Subrahmanyam, and Guadalupe Espinoza. 2012. Friending, IMing, and hanging out face-to-face: Overlap in adolescents' online and offline social networks. Developmental Psychology 48 (2): 356-368.

Shoham, David A., Liping Tong, Peter J. Lamberson, Amy H. Auchincloss, Jun Zhang, Lara Dugas, and Kathleen A. O'Connor. 2012. An actorbased model of social network influence on adolescent body size, screen time, and playing sports. PLoS ONE 7 (6): e39795. doi:10.1371/journal.pone.0039795. 
Steglich, Christian, Tom A.B. Snijders, and Patrick West. 2006. Applying SIENA. An illustrative analysis of the coevolution of adolescents' friendship networks, taste in music, and alcohol consumption. Methodology 2 (1): 48-56.

Subrahmanyam, Kaveri, Stephanie M. Reich, Natalia Waechter, and Guadalupe Espinoza. 2008. Online and offline social networks: Use of social networking sites by emerging adults. Journal of Applied Developmental Psychology 29 (6): 420-433.

van Dijk, Jan. 2006. The network society. Social aspects of new media. Thousand Oaks, CA: Sage.

van Eimeren, Birgit. 2013. 'Always on'. Smartphone, Tablet \& Co. als neue Taktgeber im Netz. Media Perspektiven 7-8: 386-390.

van Zalk, Maarten H.W., Nejra van Zalk, Margaret Kerr, and Hakan Stattin. 2014. Influences between online-exclusive, conjoint and offline-exclusive friendship networks: The moderating role of shyness. European Journal of Personality 28 (2): 134-146.

Wasserman, Stanley, and Katherine Faust. 1994. Social network analysis. Methods and applications. Cambridge: Cambridge University Press.

Weber, Mathias. 2015. Der soziale Rezipient. Wiesbaden: Springer.

Wellman, B., A., Quan-Haase, J., Boase, W., Chen, K., Hampton, I., Díaz, and K., Miyata. 2003. The Social Affordances of the Internet for Networked Individualism. Journal of Computer-Mediated Communication, 8: 0. doi:10.1111/j.1083-6101.2003.tb00216.x.

Open Access This chapter is licensed under the terms of the Creative Commons Attribution 4.0 International License (http://creativecommons.org/licenses/ by $/ 4.0 /)$, which permits use, sharing, adaptation, distribution and reproduction in any medium or format, as long as you give appropriate credit to the original author(s) and the source, provide a link to the Creative Commons license and indicate if changes were made.

The images or other third party material in this chapter are included in the chapter's Creative Commons license, unless indicated otherwise in a credit line to the material. If material is not included in the chapter's Creative Commons license and your intended use is not permitted by statutory regulation or exceeds the permitted use, you will need to obtain permission directly from the copyright holder.

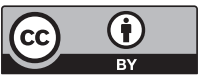

